\title{
Comparison of the ToxA test with cytotoxicity assay and culture for the detection of Clostridium difficile-associated diarrhoeal disease
}

\author{
V. SCHUÉ, G. A. GREEN* and H. MONTEIL \\ Laboratoire de Toxinologie Bactérienne, Laboratoire de Bactériologie de la Faculté de Médecine, Université Louis- \\ Pasteur, 3 rue Koeberlé, 67000 Strasbourg. France
}

\begin{abstract}
Summary. Stool samples ( 355 from 350 patients) were examined in a new commercial assay, the ToxA test, for the rapid diagnosis of Clostridium difficile-associated diarrhoea. The results were compared with direct assay of cytotoxin in McCoy cell tissue culture, and detection of toxigenic $C$. difficile by culture and cytotoxin testing of isolates. Discordant results were resolved by consultation of clinical records. Test sensitivities were $84.6 \%$ for the ToxA test, $78.5 \%$ for the direct cytotoxicity assay and $95.4 \%$ for culture. The specificity was $100 \%$ for all the tests. The ToxA test is a rapid and reliable alternative for the detection of toxigenic $C$. difficile where tissue culture facilities are unavailable.
\end{abstract}

\section{Introduction}

Antibiotic-associated diarrhoea or pseudomembranous colitis results from overgrowth in the bowel of Clostridium difficile with production of two toxins-toxin A. a lethal enterotoxin that causes haemorrhage and fluid secretion, and the cytotoxic toxin B. ${ }^{1.2}$ Confirmatory diagnosis of $C$. difficileassociated disease is best established by detecting the presence of the organism and toxin A or toxin B in stool samples. Toxin B can be detected by its cytopathic effect on tissue-culture cells and this is considered as the "gold standard" method for diagnosis of $C$. difficile diarrhoeal disease. However, the cytotoxin assay is costly, slow and requires some expertise. Alternative methods of toxin detection have been developed including latex agglutination, dot immunobinding, PCR, DNA probes and ELISA. ${ }^{3}$ In this study, a commercial monoclonal antibody (MAb)based ELISA test for toxin A was evaluated.

\section{Materials and methods}

\section{Specimens}

Stool specimens (355) collected over a period of 2 months from 350 in-patients in Strasbourg University Hospital, France, were assayed for cytotoxin and cultured for $C$. difficle on receipt, held at $4^{\circ} \mathrm{C}$ for toxin A testing (processed within $48 \mathrm{~h}$ ), and then frozen at $-80^{\circ} \mathrm{C}$ for further studies if required.

\section{Isolation and toxigenicity testing (IT culture)}

Stool specimens were inoculated onto cycloserinecefoxitin-fructose agar $(\mathrm{CCFA})^{4}$ and incubated anaerobically at $37^{\circ} \mathrm{C}$ for $48 \mathrm{~h}$. Suspect colonies were identified by the Rapid 32A system (bioMérieux, France). $C$. difficile isolates were grown anaerobically for $48 \mathrm{~h}$ at $37^{\circ} \mathrm{C}$ in $2-3 \mathrm{ml}$ of peptone-glucose-yeast (PGY) broth. The culture was centrifuged and the supernate was assayed for cytotoxin as described below.

\section{Cytotoxin assay}

Stool samples were suspended at $c .1$ in 10 dilution in sterile double-distilled water and centrifuged for $30 \mathrm{~min}$ at $2500 \mathrm{~g}$. The supernate was filtered through a $0 \cdot 45-\mu \mathrm{m}$ membrane filter (Millipore). The filtrate was added to a confluent monolayer of McCoy cells in the wells of a microtitration plate, and incubated for $24 \mathrm{~h}$ at $37^{\circ} \mathrm{C}$ in an atmosphere of $\mathrm{CO}_{2} 5.5 \%$ in air. Positive cytotoxin activity, indicated by rounding of the cells, was confirmed by neutralisation with toxin B-specific antiserum. $^{5}$

\section{ToxA test}

The ToxA test is a new commercial assay from Biowhittaker (Fontenay-sous-bois, France).

Stool samples were suspended at $c .1$ in 2 in diluent buffer and two drops (c. $100 \mu \mathrm{l})$ of the suspension were added to a microtitration well coated with toxin Aspecific polyclonal antibody. A further drop of detection reagent (toxin A-specific MAb linked to horseradish peroxidase) was added. Negative and positive controls were distributed into designated wells. If 
present, toxin $\mathrm{A}$ binds to the detecting antibody and to the immobilised polyclonal antibody during incubation at $37^{\circ} \mathrm{C}$ for $2 \mathrm{~h}$. Unbound material was removed by five washes with the supplied solution at room temperature. One drop each of substrate solution $\mathrm{A}$ (urea peroxide) and substrate solution B (tetramethylbenzidene) were added and the plates were incubated for $15 \mathrm{~min}$ at room temperature. Retention of the enzyme-antibody-antigen complex formed in the presence of toxin A was indicated by development of a yellow colour, the intensity of which was read at $450 \mathrm{~nm}$ in a Multiskan MCC/340 spectrophotometer. Optical density readings (ODs) were interpreted according to the manufacturer's guidelines: wells yielding ODs $<0.1$ were considered negative; ODs of $0 \cdot 1-0.2$ were considered equivocal, and re-tested; and wells yielding ODs $>0.2$ were considered positive for toxin A.

\section{Clinical assessment}

Clinical records were consulted for all specimens that gave discordant results in the three assays. The diagnosis of $C$. difficile-associated diarrhoea (CDAD) was considered correct if all of the following conditions were met: the patients had received an antibiotic during the previous 3 weeks; they had subsequently developed diarrhoea or liquid stools (more than three loose or watery stools a day, for at least 2 days); the diarrhoea had ceased after withdrawal of the antibiotic or after oral administration of vancomycin or metronidazole; and stool samples were positive in the IT culture, cytotoxin or ToxA assays.

\section{Results}

Of the 355 specimens tested, $47(13 \cdot 2 \%)$ gave positive results in all three assays; $290(81 \cdot 7 \%)$ gave negative results in all three assays; and $18(5 \cdot 1 \%)$ gave positive results in some, but not all assays (table I). Sixteen of the 18 patients in the latter group presented with diarrhoeal symptoms after antibiotic therapy, recovered after appropriate treatment or after withdrawal of antibiotics, and were judged to be positive for $C$. difficile (table I). The two remaining patients in this group had a diagnosis of pseudomembranous colitis confirmed by endoscopic examination; the results for one were ToxA-positive but cytotoxin- and IT culture-negative, for the other, ToxA- and IT culture-positive but cytotoxin-negative.

The ToxA test showed a sensitivity of $96 \%$ and a specificity of $98 \%$ when compared with the cytotoxin assay, and a sensitivity of $83.9 \%$ and a specificity of $99 \%$ when compared with IT culture. ToxA and cytotoxin results agreed for $97.7 \%$ of specimens, and ToxA and IT culture results agreed for $96.3 \%$ of specimens. Of the 65 specimens for patients considered to have CDAD, the ToxA test was positive for 55 , the cytotoxin assay was positive for 51 , and IT culture was
Table I. Results obtained with 355 stool specimens in three diagnostic tests for CDAD

\begin{tabular}{|c|c|c|c|c|}
\hline \multicolumn{3}{|c|}{ Assay result in } & \multirow{2}{*}{$\begin{array}{l}\text { Number of } \\
\text { stool specimens }\end{array}$} & \multirow{2}{*}{$\begin{array}{l}\text { Diagnosis of } \\
\text { CDAD* }\end{array}$} \\
\hline ToxA test & $\begin{array}{l}\text { Cytotoxin } \\
\text { assay }\end{array}$ & IT culture & & \\
\hline+ & + & + & 47 & Positive \\
\hline+ & + & - & $2^{*}$ & Positive \\
\hline+ & - & + & $5(1)$ & Positive \\
\hline - & + & + & 2 & Positive \\
\hline- & - & + & 8 & Positive \\
\hline+ & - & - & $1(1)^{*}$ & Positive \\
\hline- & - & - & 290 & Negative \\
\hline
\end{tabular}

Number of patients with pseudomembranous colitis on endoscopic examination are shown in parentheses.

* Non-cytotoxin-producing C. difficile isolated on culture.

Table II. Comparison of the three diagnostic tests after reviewing patients' record

\begin{tabular}{lrcr}
\hline & \multicolumn{3}{c}{ Assay system } \\
\cline { 2 - 4 } Criteria (\%) & ToxA & Cytotoxin & IT culture \\
\hline Sensitivity & 85 & 79 & 95 \\
Specificity & 100 & 100 & 100 \\
Positive predictive value & 100 & 100 & 100 \\
Negative predictive value & 97 & 95 & 99 \\
Correlation & 97 & 96 & 99 \\
& & & \\
\hline
\end{tabular}

positive for 62 . No false positive results were found. All three tests showed a specificity of $100 \%$; the ToxA test showed a greater sensitivity $(84.6 \%)$ than the cytotoxin assay $(78.5 \%)$, but a lower sensitivity than IT culture (95.4\%; table II).

Six specimens yielded equivocal results on initial ToxA assay; repeat tests on these specimens yielded clear negative results. All ToxA-positive stools yielded further positive results on repeat testing after freezing at $-80^{\circ} \mathrm{C}$ and thawing. Twenty-one patients $(5.9 \%)$ harboured non-toxigenic $C$. difficile strains.

\section{Discussion}

The widespread use of broad-spectrum antibiotics has led to an ever increasing incidence of pseudomembranous colitis and antibiotic-associated diarrhoea. Approximately $10 \%$ of hospitalised patients harbour $C$. difficile (unpublished data, national sample survey; Biocodex, Montrouge, France). The presence of diarrhoea and a history of recent antimicrobial therapy is only suggestive of CDAD; laboratory tests are necessary to confirm the diagnosis. Although tissue-culture assay for cytotoxin is considered the "gold standard" method for confirmation, this is a costly, slow assay that requires some expertise. IT culture is also slow and isolates must be tested for toxigenicity because of the significant incidence of carriage of non-toxigenic strains; however, this was the most sensitive $(95.4 \%)$ of the tests in this study. 
The 13 instances of cytotoxin-negative, IT culturepositive stools and two instances of IT culture-negative and cytotoxin-positive stools may be explained by the problems inherent in sampling non-homogeneous specimens. Furthermore, the isolation of both cytotoxigenic and non-cytotoxigenic $C$. difficile strains from the same stool sample has been reported elsewhere. ${ }^{6}$ Clearly, this demonstrates the possibility that picking a single colony for the toxigenicity assay might yield a false negative result.

Two cytotoxin-negative specimens came from patients with pseudomembranous colitis, one of which was ToxA-positive, but IT culture-negative. The reason is unclear but this result could be consistent with the fact that toxin A may be more relevant in the pathology of CDAD. ${ }^{\top}$ Confirmation of CDAD in multiple test systems increases detection rates, but only marginally, and at considerable cost and effort.

The results presented here (sensitivity $84.6 \%$, specificity $100 \%$ ) differ from those of a previous study comparing the ToxA test to cytotoxin assay without consultation of clinical records (sensitivity 99\%, specificity $93 \%),{ }^{8}$ and also differ from the values of sensitivity $93 \%$, specificity $91 \%$ found in a study in which the same criteria as in this study were used for the diagnosis of CDAD. ${ }^{9}$ The discrepant sensitivities of the cytotoxin assay in different laboratories may be due to differences in methodology, particularly the sensitivity of the cell line, ${ }^{10}$ the age of the cells and specimen preparation. Similarly divergent results were found in studies with the Premier enzyme immunoassay for toxin $\mathrm{A}$, where sensitivity estimates ranged from 40 to $92 \%$, and specificity estimates from 96 to $99.5 \% .^{11}$

We consider that the ToxA test is a valuable option for those laboratories without facilities for tissue culture. It combines speed ( $30 \mathrm{~min}$ of processing time and $2 \mathrm{~h}$ of incubation for 20 samples) and requires little technical expertise. The ToxA test has excellent specificity and very good sensitivity compared with the cytotoxicity assay and culture for $C$. difficile. This test can be used alone or combined with other tests.

This work was supported in part by Institut National de la Santé et de la Recherche Médicale grant number 900316 .

8. Altaie SS, Meyer P, Dryja D. Comparison of two commercially available enzyme immunoassays for detection of Clostridium difficile in stool specimens. $J$ Clin Microbiol $1994 ; 32:$ 51-53.

9. Whittier S, Shapiro DS, Kelly WF et al. Evaluation of four commercially available enzyme immunoassays for laboratory diagnosis of Clostridium difficile-associated diseases. J Clin Microbiol 1993; 31 : 2861-2865.

10. Maniar AC, Williams TW, Hammond GW. Detection of Clostridium difficile toxin in various tissue culture monolayers. J Clin Microbiol 1987; 25 : 1999-2000.

11. Doern GV, Coughlin RT, Wu L. Laboratory diagnosis of Clostridium difficile-associated gastrointestinal disease: comparison of a monoclonal antibody enzyme immunoassay for toxins $\mathbf{A}$ and $\mathbf{B}$ with a monoclonal antibody enzyme immunoassay for toxin A only and two cytotoxicity assays. J Clin Microbiol 1992; 30 : 2042-2046. 